\title{
DESENVOLVIMENTO DE MARACUJAZEIRO-AMARELO ENXERTADO SOBRE MARACUJAZEIRO-DOCE EM DIFERENTES ESPAÇAMENTOS DE PLANTIO
}

\author{
MAURICIO DOMINGUEZ NASSER ${ }^{1}$ JOSÉ CARLOS CAVICHIOLI $^{2}$, \\ FRANCISCO SEIITI KASAI ${ }^{3}$, RODRIGO VITORINO
}

RESUMO - O objetivo deste trabalho foi avaliar o efeito de diferentes espaçamentos de plantio no desenvolvimento do maracujazeiro-amarelo (Passiflora edulis Sims) enxertado sobre o maracujazeiro-doce (Passiflora alata Curtis) em área com histórico de morte prematura de plantas. O experimento foi conduzido no município de Adamantina-SP, no período de abril de 2008 a junho de 2009, adotando-se o delineamento em blocos ao acaso, com seis tratamentos e quatro repetições. Os tratamentos constituíram-se de diferentes espaçamentos na linha de plantio: T1-1,0 m (3.125 plantas/ha); T2-1,5 m (2.083 plantas/ha); T3- 2,0 m (1.563 plantas/ha); T4-3,0 m (1.042 plantas/ha); T5- 4,0 m (781 plantas/ha), e T6- 5,0 m (625 plantas/ha). $\mathrm{O}$ espaçamento nas entrelinhas foi de 3,2 $\mathrm{m}$ de largura em todos os tratamentos. Avaliaram-se o diâmetro do caule do porta-enxerto, o diâmetro do caule do enxerto, o comprimento de entrenó, o comprimento dos ramos secundários e o número de ramos terciários. O adensamento de plantas não favoreceu o desenvolvimento de plantas enxertadas.

Termos para indexação: densidade de plantas, maracujá, enxertia.

\section{GROWTH OF YELLOW PASSION FRUIT GRAFTED ON SWEET PASSION FRUIT IN DIFFERENT PLANTING SPACING}

\begin{abstract}
The objective of this work was to evaluate the vegetative growth of yellow passion fruit grafted on sweet passion fruit, in different plant spacing, in area with description of premature death of plants. The experiment was carried out in Adamantina, SP, Brazil, from April 2008 to June 2009, adopting the randomized experimental design, with six treatments and four replications. The treatments were different planting spacing: T1, 1,0 $\mathrm{m}$ (3.125 plants/ha); T2, 1,5 m (2.083 plants/ha); T3, 2,0 $\mathrm{m}$ (1.563 plants/ha); T4, 3,0 m (1.042 plants/ha); T5, 4,0 m (781 plants/ha) and T6, 5,0 m (625 plants/ha). The distance between the lines was $3,2 \mathrm{~m}$ for all the treatments. The variables evaluated were: rootstocks and grafts stem diameter, internode length, secondary branches length and tertiary branches number. Planting density did not favor the growth of the rootstocks plants.
\end{abstract}

Index terms: planting densities, passion fruit, grafting.

\section{INTRODUÇÃO}

A cultura do maracujazeiro-amarelo representa uma importante atividade econômica para a região oeste do Estado de São Paulo, explorada principalmente no contexto da agricultura familiar. Porém, nos últimos anos, esta cultura vem sofrendo com vários problemas de ordem fitossanitária, como a morte prematura de plantas.
A morte súbita ou prematura é atribuída à associação de fungos de solo, nematoides e bactéria, como Xanthomonas axonopodis pv. passiflorae, que se manifesta e dizima rapidamente as plantas quando estas entram em produção (LIBERATO, 2002).

Técnica descrita por diversos autores (CHAVES et al., 2004; SILVA et al., 2005, CAVICHIOLI et al., 2009) e que pode ser empregada no controle de

\footnotetext{
${ }^{1}$ Trabalho Sinfruit 013 - Simpósio Internacional de Fruticultura - Avanços na Fruticultura (17 a 21 Outubro)

${ }^{2}$ Pesquisador da APTA Regional Alta Paulista, Caixa Postal 191, 17.800-000, Adamantina (SP), fone: (18) 3521-4800. E-mail: mdnasser@apta.sp.gov.br

${ }^{3}$ Pesquisador da APTA Regional Alta Paulista, Caixa Postal 191, 17.800-000, Adamantina (SP), fone: (18) 3521-4800. E-mail: jccvichioli@apta.sp.gov.br

${ }^{4}$ Pesquisador da APTA Regional Alta Paulista, Caixa Postal 191, 17.800-000, Adamantina (SP), fone: (18) 3521-4800. E-mail: fskasai@apta.sp.gov.br

${ }^{5}$ Graduando em Agronomia FAI, Adamantina, SP. E-mail: rodrigo_vitorino10@hotmail.com
} 
fungos patógenos de solo (JUNQUEIRA et al., 2006), a enxertia pode viabilizar o cultivo do maracujazeiro-amarelo em área com histórico de morte prematura de plantas.

Os materiais mais promissores são $P$. alata e P. gibertii (OLIVEIRA et al., 1984; RONCATTO et al., 2004). Maldonado e Dias (2008) recomendam o uso de $P$. alata para reduzir a morte de plantas por Fusarium solani.

Desta forma, tem-se procurado estudar aspectos relativos à produção de mudas enxertadas, compatibilidade entre enxerto e porta-enxerto e sobrevivência de plantas no campo. Mas ainda são pequenos o número de espécies testadas e os resultados obtidos, necessitando de trabalhos envolvendo as fases de crescimento e produção.

A densidade de plantas na linha de plantio é um dos fatores que interfere na eficiência técnica e econômica de uma cultura. De acordo com Andrade Júnior et al. (2003), o adensamento de plantio em maracujazeiro permite maior produtividade nas primeiras safras, porém a produtividade deve ser acompanhada de maior retorno econômico.

Considerando que a morte prematura de plantas constitui-se em um importante problema a ser solucionado no cultivo do maracujazeiro, evitando assim a redução da produtividade e a diminuição da área de plantio, associado com os resultados satisfatórios apresentados com a técnica da enxertia em espécies tolerantes, objetivou-se, neste trabalho, avaliar diferentes espaçamentos de plantio do maracujazeiro-amarelo enxertado sobre o maracujazeiro-doce em área com histórico de morte prematura de plantas.

\section{MATERIAL E MÉTODOS}

O experimento foi conduzido em uma propriedade localizada no município de Adamantina-SP, na região da Nova Alta Paulista, no período de abril de 2008 a junho de 2009. O solo da área experimental foi classificado como Argissolo Vermelho-Amarelo, eutrófico, A moderado, textura arenosa/média e topografia ondulada.

O clima da região é Cwa, segundo a classificação de Köeppen, com estação chuvosa no verão e estação seca no inverno. A precipitação média anual é de $1.300 \mathrm{~mm}$. A temperatura média anual está em torno de $22-23^{\circ} \mathrm{C}$, a do mês mais quente é em torno de $26^{\circ} \mathrm{C}$ e a do mês mais frio está por volta de 17 $18^{\circ} \mathrm{C}$.

O experimento foi conduzido em área com histórico de morte prematura de plantas, utilizando- -se de plantas de maracujazeiro-amarelo (Passiflora edulis Sims) enxertadas sobre o maracujazeiro-doce (Passiflora alata Curtis), adotando-se o delineamento estatístico em blocos ao acaso, com seis tratamentos e quatro repetições. Utilizou-se a enxertia hipocotiledonar por garfagem tipo fenda cheia. Os tratamentos constituíram-se de diferentes espaçamentos na linha de plantio: T1-1,0 m (3.125 plantas/ha); T2-1,5 m (2.083 plantas/ha); T3-2,0 m (1.563 plantas/ha); T43,0 m (1.042 plantas/ha); T5- 4,0 m (781 plantas/ha), e T6- 5,0 m (625 plantas/ha)

O plantio das mudas foi realizado no dia 23 de abril de 2008, no espaçamento de 3,2 m nas entrelinhas. As plantas foram conduzidas com um único ramo vegetativo (ramo primário) até atingir o segundo fio de arame, sendo que as brotações laterais foram eliminadas.

Foram avaliadas as seguintes características: a) Diâmetro do caule do porta-enxerto e do enxerto: com o auxílio de um paquímetro de precisão de $0,1 \mathrm{~mm}$, mediu-se a $1 \mathrm{~cm}$ do colo (porta-enxerto) e a $15 \mathrm{~cm}$ do colo (enxerto). As avaliações foram realizadas aos 30; 60; 90 e 360 dias do plantio das mudas no campo.

b) Comprimento do entrenó: foi obtido pela divisão do comprimento do enxerto pelo número de nós.

c) Comprimento dos ramos secundários: foi realizado com uma régua graduada $\mathrm{em} \mathrm{mm}$, medindo da inserção com o ramo principal até o ponteiro, aos 150 dias. d) Número de ramos terciários: contou-se o número de ramos terciários aos 150 dias.

\section{RESULTADOS E DISCUSSÃO}

Nas avaliações do diâmetro do caule do porta-enxerto, não foram observadas diferenças estatísticas entre os tratamentos (Tabela 01). Aos 30 dias de idade de plantio no campo, o diâmetro do caule variou de $6,13 \mathrm{~mm}$ no espaçamento de $1,0 \mathrm{~m}$, a $6,79 \mathrm{~mm}$ no espaçamento de $4,0 \mathrm{~m}$ entre plantas. $\mathrm{Na}$ avaliação dos 60 dias, o diâmetro variou de $8,81 \mathrm{~cm}$ no espaçamento de $1,5 \mathrm{~m}$, a $9,59 \mathrm{~mm}$ no espaçamento de 2,0 m entre plantas. Aos 90 dias, variou de 9,71 a $10,10 \mathrm{~mm}$ e, finalmente, aos 360 dias de plantio no campo, variou de $35,05 \mathrm{~mm}$ no espaçamento de $1,0 \mathrm{~m}$, a $42,33 \mathrm{~mm}$ no espaçamento de 4,0 $\mathrm{m}$ entre plantas. Esses valores foram superiores aos obtidos por Nogueira Filho et al. (2010) na avaliação dos 30 dias, que variaram de 4,96 a $5,92 \mathrm{~mm}$, trabalhando com seis espécies de passifloras na região de Jaboticabal; mas, nas avaliações dos 60 e 90 dias, ficaram dentro da faixa dos resultados encontrados por estes autores. 
O diâmetro do caule do enxerto, medido a 15 $\mathrm{cm}$ de altura do caule, também não apresentou diferenças entre os espaçamentos adotados nas avaliações realizadas aos 30; 60 e 90 dias de plantio no campo (Tabela 2). Variou de 4,82 $\mathrm{mm}$ no espaçamento de $5 \mathrm{~m}$ entre plantas, a $5,18 \mathrm{~mm}$ no espaçamento de $2,0 \mathrm{~m}$ aos 30 dias. Na avaliação dos 60 dias, variou de $6,27 \mathrm{~mm}$ no espaçamento de $5,0 \mathrm{~m}$, a $7,12 \mathrm{~mm}$ no espaçamento de $2,0 \mathrm{~m}$ entre plantas, e aos 90 dias, variou de $6,22 \mathrm{~mm}$ a $7,26 \mathrm{~mm}$. Entretanto, aos 360 dias, houve diferenças entre os diâmetros, verificando-se o menor diâmetro do caule do enxerto no espaçamento entre plantas de 1,0 e 2,0 m, que diferiram do espaçamento de 4,0 m entre plantas (Tabela 01). Estes valores ficaram dentro da faixa encontrada por Nogueira Filho et al. (2010), para a avaliação dos 30 dias, que, trabalhando com seis espécies de Passifloras na região de Jaboticabal, observaram diâmetros que variaram de $3,50 \mathrm{~mm}$ a 4,26 mm. Já, para as avaliações realizadas aos 60 e 90 dias, os resultados foram inferiores aos encontrados por estes autores.

Não houve diferenças estatísticas entre os tratamentos para o comprimento do entrenó, que variou de $6,52 \mathrm{~cm}$ nos espaçamentos de 1,5 e 2,0 m, a $6,95 \mathrm{~cm}$ no espaçamento de $3,0 \mathrm{~m}$ entre plantas.

Observou-se o menor comprimento dos ramos secundários no espaçamento de $1,5 \mathrm{~m}$ entre plantas, com 139,10 cm, diferindo dos espaçamentos de 3,0 e 4,0 m, com 191,00 e 189,88 cm, respectivamente. $\mathrm{O}$ número de ramos terciários variou de 10 no espaçamento de $5,0 \mathrm{~m}$, a 16,5 no espaçamento de 3,0 entre plantas, não apresentando diferenças entre os tratamentos.

TABELA 01 - Diâmetro do caule do porta-enxerto, em mm, medido a $1 \mathrm{~cm}$ do colo, de plantas de maracujazeiro-amarelo enxertadas sobre maracujazeiro-doce, aos 30; 60; 90 e 360 dias do plantio no campo. Adamantina-SP, 2008-2009.

\begin{tabular}{cccccc}
\hline $\begin{array}{l}\text { Espaçamento }(\mathrm{m}) \\
\text { Linha x planta }\end{array}$ & Plantas/ha & 30 dias & 60 dias & 90 dias & 360 dias \\
\hline $3,2 \times 1,0$ & 3.125 & 6,13 & 8,95 & 10,06 & 35,05 \\
$3,2 \times 1,5$ & 2.083 & 6,51 & 8,81 & 9,71 & 38,95 \\
$3,2 \times 2,0$ & 1.563 & 6,63 & 9,59 & 10,03 & 37,48 \\
$3,2 \times 3,0$ & 1.042 & 6,29 & 9,09 & 10,10 & 41,45 \\
$3,2 \times 4,0$ & 781 & 6,79 & 9,01 & 10,09 & 42,33 \\
$3,2 \times 5,0$ & 625 & 6,24 & 8,89 & 9,68 & 40,95 \\
\hline F & & $0,92 \mathrm{~ns}$ & $1,42 \mathrm{~ns}$ & $0,25 \mathrm{~ns}$ & $2,88 \mathrm{~ns}$ \\
CV (\%) & 8,16 & 5,17 & 7,97 & 8,26 \\
DMS & 1,21 & 1,08 & 1,82 & 7,47 \\
\hline
\end{tabular}

Médias seguidas de mesmas letras na coluna não diferem entre si, significativamente, ao nível de $5 \%$ de probabilidade, pelo Teste de Tukey. ns - não significativo

TABELA 02 - Diâmetro do caule do enxerto, em mm, medido a $15 \mathrm{~cm}$ do colo, de plantas de maracujazeiro-amarelo enxertadas sobre maracujazeiro-doce, aos 30; 60; 90 e 360 dias do plantio no campo. Adamantina-SP, 2008-2009.

\begin{tabular}{|c|c|c|c|c|c|}
\hline $\begin{array}{l}\text { Espaçamento } \\
(\mathrm{m})\end{array}$ & Plantas/ha & 30 dias & 60 dias & 90 dias & 360 dias \\
\hline $3,2 \times 1,0$ & 3.125 & 4,91 & 6,57 & 6,85 & $22,75 \mathrm{~b}$ \\
\hline $3,2 \times 1,5$ & 2.083 & 4,92 & 6,51 & 6,71 & $25,38 \mathrm{ab}$ \\
\hline $3,2 \times 2,0$ & 1.563 & 5,18 & 7,12 & 6,22 & $24,53 \mathrm{~b}$ \\
\hline $3,2 \times 3,0$ & 1.042 & 4,84 & 6,86 & 6,98 & $28,10 \mathrm{ab}$ \\
\hline $3,2 \times 4,0$ & 781 & 4,96 & 6,83 & 7,26 & $30,43 \mathrm{a}$ \\
\hline $3,2 \times 5,0$ & 625 & 4,82 & 6,27 & 6,56 & $28,08 \mathrm{ab}$ \\
\hline $\mathrm{F}$ & & $0,56 \mathrm{~ns}$ & $1,02 \mathrm{~ns}$ & $1,58 \mathrm{~ns}$ & $5,16 * *$ \\
\hline CV $(\%)$ & & 7,04 & 8,92 & 6,35 & 9,34 \\
\hline DMS & & 0,80 & 1,37 & 1,01 & 5,70 \\
\hline
\end{tabular}

Médias seguidas de letras distintas na coluna diferem entre si, significativamente, ao nível de $5 \%$ de probabilidade, pelo Teste de Tukey. ns - não significativo

** - significativo ao nível de $1 \%$ de probabilidadE 
TABELA 03 - Comprimento do entrenó, aos 360 dias do plantio, comprimento do ramo secundário e número de ramos terciários, aos 150 dias do plantio, de plantas de maracujazeiro-amarelo enxertadas sobre maracujazeiro-doce. Adamantina-SP, 2008-2009.

\begin{tabular}{ccccc}
\hline $\begin{array}{c}\text { Espaçamento } \\
(\mathrm{m})\end{array}$ & Plantas/ha & $\begin{array}{c}\text { Comprimento do } \\
\text { entrenó }(\mathrm{cm})\end{array}$ & $\begin{array}{c}\text { Comprimento de ramo } \\
\text { secundário }(\mathrm{cm})\end{array}$ & $\begin{array}{c}\text { Número de ramos } \\
\text { terciários }\end{array}$ \\
\hline linha x planta & 3.125 & 6,69 & $172,28 \mathrm{ab}$ & 12,73 \\
$3,2 \times 1,0$ & 2.083 & 6,52 & $139,10 \mathrm{~b}$ & 13,38 \\
$3,2 \times 1,5$ & 1.563 & 6,52 & $172,88 \mathrm{ab}$ & 13,00 \\
$3,2 \times 2,0$ & 1.042 & 6,95 & $191,00 \mathrm{a}$ & 16,50 \\
$3,2 \times 3,0$ & 781 & 6,60 & $189,88 \mathrm{a}$ & 14,50 \\
$3,2 \times 4,0$ & 625 & 6,61 & $155,38 \mathrm{ab}$ & 10,00 \\
$3,2 \times 5,0$ & & $0,67 \mathrm{~ns}$ & $4,42 *$ & $1,82 \mathrm{~ns}$ \\
F & & 5,86 & 11,23 & 23,83 \\
CV (\%) & 0,89 & 43,88 & 7,31 \\
\hline
\end{tabular}

Médias seguidas de letras distintas na coluna diferem entre si, significativamente, ao nível de $5 \%$ de probabilidade, pelo Teste de Tukey. * significativo ao nível de $5 \%$ de probabilidade

ns - não significativo

\section{CONCLUSÃO}

O adensamento de plantas não favorece o desenvolvimento de plantas enxertadas. O melhor desenvolvimento das plantas foi observado no espaçamento de $4,0 \mathrm{~m}$ entre plantas.

\section{REFERENCIAS}

ANDRADE JUNIOR, V.C. de; ARAUJO NETO, S.E. de; RUFINI, J.C.M.; RAMOS, J.D. Produção de maracujazeiro-amarelo sob diferentes densidades de plantio. Pesquisa Agropecuária Brasileira, Brasília, v.38, n.12, p.1381-1386, 2003.

CAVICHIOLI, J.C.; CORRÊA, L. de S.; BOLIANI, A.C.; OLIVEIRA, J.C. de. Uso de câmara úmida em enxertia hipocotiledonar de maracujazeiro-amarelo sobre três porta-enxertos. Revista Brasileira de Fruticultura, Jaboticabal, v.31, n.2, p.532-538, 2009.

CHAVES, R.C.; JUNQUEIRA, N.T.V.; MANICA, I.; PEIXOTO, J.R.; PEREIRA, A.V.; FIALHO, J.F. Enxertia de maracujazeiro-azedo em estacas herbáceas enraizadas de espécies de passifloras nativas. Revista Brasileira de Fruticultura, Jaboticabal, v.26, n.1, p.120-123, 2004.
JUNQUEIRA, N.T.V.; LAGE, D.A. da C.; BRAGA, M.F.; PEIXOTO, J.R.; BORGES, T.A.; ANDRADE, S.R.M. de. Reação a doenças e produtividade de um clone de maracujazeiro-azedo propagado por estaquia e enxertia em estacas herbáceas de Passiflora silvestre. Revista Brasileira de Fruticultura, Jaboticabal, v.28, n.1, p.97-100, 2006.

LIBERATO, J.R. Controle das doenças causadas por fungos, bactérias e nematoides em maracujazeiro. In: ZAMBOLIM, L.; VALE, F.X.R.; MONTEIRO, A.J.A.; COSTA, H. (Org.). Controle de doenças de plantas fruteiras. Viçosa: UFV, 2002. v.2, p.699-825.

MALDONADO, J.F.M.; DIAS, V.M. Enxertia de maracujazeiro-amarelo (Passiflora edulis Sims f. flavicarpa Deg.) no Noroeste Fluminense. In: CONGRESSO BRASILEIRO DE FRUTICULTURA, 20, Vitória, 2008. Anais... Vitória: SBF/INCAPER, 2008. CD-ROM.

NOGUEIRA FILHO, G.C.; RONCATTO, G.; RUGGIERO, C.; OLIVEIRA, J.C. de; MALHEIROS, E.B. Desenvolvimento e produção das plantas de maracujazeiro-amarelo produzidas por enxertia hipocotiledonar sobre seis porta-enxertos. Revista Brasileira de Fruticultura, Jaboticabal, v.32, n.2, p.535-543, 2010. 
OLIVEIRA, J.C.; RUGGIERO, C.; NAKAMURA, K.; BAPTISTA, M. Comportamento de Passiflora edulis enxertada sobre $P$. gibertii N.E. Brown. In: CONGRESSO BRASILEIRO DE FRUTICULTURA, 7, 1983, Florianópolis. Anais...Florianópolis: EMPASC/SBF, 1984. v.3. p.989-993.

RONCATTO, G.; OLIVEIRA, J.C.de, R.C.; NOGUEIRA FILHO, G.C.; CENTURION, M.A.P.da C.; FERREIRA, F.R. Comportamento de maracujazeiros (Passiflora spp.) quanto à morte prematura. Revista Brasileira de Fruticultura, Jaboticabal, v.26, n.3, p.552-554, 2004.
SILVA, F.M.; CORRÊA, L.de S.; BOLIANI, A.C.; SANTOS, P.C. dos. Enxertia de mesa de Passiflora edulis Sims f. flavicarpa Deg. sobre Passiflora alata Curtis, em ambiente de nebulização intermitente.

Revista Brasileira de Fruticultura, Jaboticabal, v.27, n.1, p.98-101, 2005. 